\title{
BMJ Open Higher incidence of adverse events in isolated patients compared with non- isolated patients: a cohort study
}

\author{
Fátima Jiménez-Pericás (1) , ${ }^{1}$ María Teresa Gea Velázquez de Castro, ${ }^{1}$ \\ María Pastor-Valero, ${ }^{2,3}$ Carlos Aibar Remón, ${ }^{4,5}$ Juan José Miralles, ${ }^{2}$ \\ María del Carmen Meyer García, ${ }^{6}$ Jesús Maria Aranaz Andrés ${ }^{3,7}$
}

To cite: Jiménez-Pericás $F$, Gea Velázquez de Castro MT, Pastor-Valero M, et al. Higher incidence of adverse events in isolated patients compared with non-isolated patients: a cohort study. BMJ Open 2020;10:e035238. doi:10.1136/ bmjopen-2019-035238

- Prepublication history for this paper is available online. To view these files, please visit the journal online (http://dx.doi. org/10.1136/bmjopen-2019035238).

Received 25 April 2020 Revised 28 September 2020 Accepted 02 0ctober 2020

Check for updates

(C) Author(s) (or their employer(s)) 2020. Re-use permitted under CC BY-NC. No commercial re-use. See rights and permissions. Published by BMJ.

For numbered affiliations see end of article.

Correspondence to Fátima Jiménez-Pericás; jimper75@hotmail.com

\section{ABSTRACT}

Objective To determine whether isolated patients admitted to hospital have a higher incidence of adverse events (AEs), to identify their nature, impact and preventability.

Design Prospective cohort study with isolated and nonisolated patients.

Setting One public university hospital in the Valencian Community (southeast Spain).

Participants We consecutively collected 400 patients, 200 isolated and 200 non-isolated, age $\geq 18$ years old, to match according to date of entry, admission department, sex, age ( \pm 5 years) and disease severity from April 2017 to October 2018. Exclusion criteria: patients age $<18$ years old and/or reverse isolation patients.

Primary and secondary outcome measures The primary outcome as the $\mathrm{AE}$, defined according to the National Study of Adverse Effects linked to Hospitalisation (Estudio Nacional Sobre los Efectos Adversos) criteria. Cumulative incidence rates and $A E$ incidence density rates were calculated.

Results The incidence of isolated patients with AEs 16.5\% (95\% Cl $11.4 \%$ to $21.6 \%$ ) compared with $9.5 \%$ (95\% Cl $5.4 \%$ to $13.6 \%)$ in non-isolated $(p<0.03)$. The incidence density of patients with AEs among isolated patients was 11.8 per 1000 days/patient $(95 \% \mathrm{Cl} 7.8$ to 15.9$)$ compared with 4.3 per 1000 days/patient $(95 \% \mathrm{Cl} 2.4$ to 6.3$)$ among non-isolated patients $(\mathrm{p}<0.001)$. The incidence of AEs among isolated patients was $18.5 \%$ compared with $11 \%$ for nonisolated patients $(p<0.09)$. Among the $37 \mathrm{AEs}$ detected in 33 isolated patients, and the $22 \mathrm{AEs}$ detected in 19 non-isolated patients, most corresponded to healthcare-associated infections (HAls) for both isolated and non-isolated patients (48.6\% vs $45.4 \%)$. There were significant differences with respect to the preventability of $\mathrm{AEs},(67.6 \%$ among isolated patients compared with $52.6 \%$ among non-isolated patients). Conclusions AEs were significantly higher in isolated patients compared with non-isolated patients, more than half being preventable and with HAls as the primary cause. It is essential to improve training and the safety culture of healthcare professionals relating to the care provided to this type of patient.

\section{INTRODUCTION}

Isolation precautions are an effective and simple method to achieve improved patient safety and infection control, minimising

\section{Strengths and limitations of this study}

- This is the first prospective cohort study to examine the incidence of adverse events (AEs) in isolated and non-isolated patients in our clinical setting.

- Our study also included patients in isolation because of colonisation with multidrug-resistant microorganisms, and was not limited to patients with infections

- The sample size included 400 patients, a larger sample size than previous studies.

- Those inherent to medical records, such as missing data and limited predetermined information included in the AE Monitoring and Control (Sistema de Información para la Vigilancia y Control de Efectos Adversos" (SIVCEA)) System database.

- Potential misclassification error might also have occurred based on wrong clinical judgements made by the reviewer of clinical records, although there was found to be good concordance between the reviewers of the medical records.

the potential of microorganism crosscontamination in the hospital setting and reducing healthcare-associated infections (HAIs). However, the application of these precautions, as well as entailing an increase in the consumption of resources, may not be without risks. ${ }^{12}$

Isolation precautions for preventing contamination through contact, droplets or by airborne transmission involve the application of specific patient-handling protocols. These include the use of physical barriers on healthcare staff, such as masks, gloves, gowns and eye protection and limits on patient visits. ${ }^{1}$ This scenario entails a series of attitudes and beliefs in healthcare staff that may affect the handling, care and safety of the isolated patient. Among the factors that can influence healthcare staff are fear of self-contamination, work overload due to the time involved in preparing adequately to 
care for this type of patient, and insecurity associated with scant specific training. ${ }^{2}$

Some studies suggest that isolation could be associated with patient safety incidents. ${ }^{3-8}$ These incidents include adverse events (AEs) and incidents that cause harm to the patient, as well as those incidents that, even though they may not have caused harm, could cause harm in other situations (incident without harm).$^{9}$

A systematic review which included 16 studies on the impact of isolation policies on patient safety, psychological well-being, satisfaction, as well as the time spent by professionals on patient care, showed a negative impact on psychological well-being, including higher rates of depression and anxiety in isolated patients compared with nonisolated patients. ${ }^{3}$ Furthermore, a higher number of errors from health professionals during the isolated patients' healthcare were observed, including a higher proportion of days without nurses' progress notes $(14 \%$ vs $10 \%$; $\mathrm{p}<0.001)$ or medical progress data (26\% vs $13 \%$; $\mathrm{p}<0.001)$. Moreover, when compared with non-isolated patients, those who were isolated had double the probability of suffering an $\mathrm{AE}$ for each 1000 days in hospital ( 31 vs $15 ; \mathrm{p}<0.001$ ), and eight times higher probability of experiencing falls, pressure ulcers or electrolyte imbalances. ${ }^{1}$

Thus, recommending 'isolation' for a patient may entail greater resource consumption along with a decrease in the frequency and healthcare quality for patients with higher incidences of HAI and levels of dissatisfaction with the healthcare provided. ${ }^{34}$ In fact, a recent systematic review and meta-analysis has shown that there were a number of apparently negative aspects to contact precautions, in particular with regard to psychological effects and a reduction in the quality of some aspects of care. ${ }^{10}$

The objective of this study was to determine whether there was a higher incidence of AEs in isolated patients compared with patients not subject to isolation who had been admitted to a public university hospital, and whether the AEs differ in terms of nature, impact and preventability.

\section{MATERIAL AND METHODS \\ Design \\ Prospective cohort study.}

\section{Setting}

The target population were residents in the catchment area of Sant Joan d'Alacant Public University Hospital, which covers a population of 234424 and has a total of 390 beds in the region of Valencia (southeast Spain). This is a referral hospital which belongs to the National Health System (Sistema Nacional de Salud, SNS) and attends all individuals living in its catchment area. The majority of the population in Spain $(98.5 \%)$ uses the SNS as their main medical service.

\section{Participants}

We prospectively collected data from consecutive isolated and non-isolated patient $\geq 18$ years old admitted between April 2017 and October 2018.

Isolated patients were those submitted to infection control precautions based on transmission (contact, airborne or droplets) at some time during their hospital stay. Non-isolated patients were those who underwent standard precautions and were not subject to isolation during their hospital stay. Isolated patients and nonisolated patients were selected consecutively to match according to date of admission, department, sex, age $( \pm 5$ years) and severity, measured using the McCabe scale (used in the Estudio de Prevalencia de las Infecciones Nosocomiales en España (EPINE) study) ${ }^{11}$

\section{Exclusion criteria}

Patients $<18$ years old and/or reverse isolation patients.

\section{Patients and public involvement}

Neither patients nor the public were involved in the design, conduct, reporting or dissemination plans of our research. Data from patients participating in this study were collected from clinical records. Therefore, patients were not interviewed nor did they have any contact with any of the researchers of this study.

\section{Sample size}

According to the cohort study published by Stelfox et al, ${ }^{1}$ the relative risk in isolated patients for any type of $\mathrm{AE}$ was 2.2. Based on this data and accepting an alpha risk of 0.05 and a beta risk of 0.2 in a bilateral contrast, at least 176 subjects are required in the exposed group and 176 in the non-exposed group in order to detect a relative minimum risk of 2.2, the incidence in patients with an $\mathrm{AE}$ in the nonexposed group being 9.3\%, taking the results of the Estudio Nacional Sobre los Efectos Adversos (ENEAS) study. ${ }^{12}$ In our study, a total sample of 400 patients (200 isolated patients and 200 non-isolated patients) was selected.

\section{Data collection}

We used the Incident Screening Guidelines to identify possible AEs. These guidelines were validated by the IDEA (Identificación de Efectos Adversos) project and used in the ENEAS study. ${ }^{12-14}$ Finally, we used the modular review form $(\mathrm{MRF} 1)^{10}$ to review patients' clinical histories. When the patient was discharged, the MRF2 ${ }^{15}{ }^{16}$ was used as a confirmatory questionnaire with which an exhaustive analysis of the $\mathrm{AE}$ and its associated circumstances was undertaken. The data were collected by the trained staff.

\section{Variables}

Exposure variable

Isolation precautions according to transmission mechanism with duration of at least 48 hours and based on the Centers for Disease Control and Prevention (CDC) definitions. ${ }^{17}$ 
Outcome variable

AE defined according to the ENEAS criterion as any unforeseen or unexpected accident included in the clinical history that has caused injury and/or incapacity and/or prolongation of the hospital stay and/or exitus, which derives from the healthcare provided and not the patient's base disease.

To determine whether the $\mathrm{AE}$ is due to healthcare, the reviewers scored them on a 6 -point scale $(1=$ no or little evidence that the $\mathrm{AE}$ was due to patient handling; $6=$ full evidence that the $\mathrm{AE}$ was due to patient handling). A score greater than or equal to 4 was required for it to be defined as an AE due to healthcare.

The preventability of each AE was determined by the reviewer by means of a 6 -point scale ( $1=$ absence of evidence of the possibility of prevention; $6=$ full evidence of the possibility of prevention).

\section{Other covariates}

Age, sex, the patient's baseline health status and length of hospital stay. We also collected the type of isolation (contact, droplets and airborne $)^{13}$ the cause of isolation (carrier, colonisation, infection) and the presence or otherwise of a multi-resistant germ.

Extrinsic risk factors such as: urinary catheter, peripheral venous catheter, arterial catheter, peripherally inserted central catheter, central venous catheter, parenteral nutrition, enteral nutrition, percutaneous endoscopic gastrostomy, nasogastric tube, tracheotomy, mechanical ventilation, immunosuppressive therapy, infusion pump, haemodialysis, peritoneal dialysis, paracentesis therapy, immobilisation, sedation and number of drugs as regular medication.

Intrinsic risk factors such as: coma, hepatic cirrhosis, coronary heart disease, renal insufficiency, drug addiction, hypertension, diabetes, obesity, hypercholesterolaemia, neoplasia, hypoalbuminaemia/malnutrition, immunodeficiency/AIDS, pressure ulcer, alcoholism, chronic lung disease, sensory impairments, ABVD dependent, neutropenia, cardiac insufficiency, dementia, pregnancy, peripheral vascular disease, skin disorder, motor impairment (neurological or rheumatic), altered consciousness (stupor, confusion), urinary incontinence, faecal incontinence, active smoking, social problems, psychiatric disease in active phase.

\section{Statistical analysis}

The characteristics of the study population have been described by means of the use of absolute and relative frequencies (percentages) in the case of qualitative variables. The quantitative variables have been expressed by means of the mean and SD (variables that follow a normal distribution) or by means of the median and IQR (variables that do not follow a normal distribution).

Cumulative incidence rates and $\mathrm{AE}$ incidence density rates have been calculated, with their respective $95 \%$ CIs and the association between the result variables and the rest of the variables being studied was measured by means of a bivariate analysis.

Logistic regression was used to analyse the independent variables relating to the development, or not, of an AE. This has allowed us to control the confusion effect, or the interaction of some variables. For all the tests used, a statistical significance for values of $\mathrm{p}<0.05$ was established.

\section{RESULTS}

Table 1 shows the characteristics of the population studied. There were 400 patients, 200 isolated and 200 non-isolated, selected prospectively and consecutively. Of these 400 patients, 209 were women $(52.2 \%, 104$ isolated and 105 non-isolated) and 191 were men $(47.8 \%, 96$ isolated and 95 non-isolated). The median age for both groups (isolated and non-isolated) was 75. Statistically significant differences were not found in relation to the presence of extrinsic factors, or in the mean length of hospital stay of isolated compared with non-isolated patients. However, among isolated patients, $75.5 \%$ had three or more risk factors compared with $64.5 \%$ in nonisolated patients ( $p$ 0.02).

The median length of hospital stay for both groups was the same (9 days). The total mean isolation time was 11.7 days, with a mean of 12.3 days for colonised patients and 11.3 days for infected patients $(\mathrm{p}=0.07)$. The most frequent type of isolation was contact isolation $(198 / 200$ patients, $99 \%$ ) of which $35.8 \%$ were colonised and $64.1 \%$ were infected. In 74 patients (37\%), the type of isolation was droplet transmission of which $14.9 \%$ were colonised cases and $85.1 \%$ were infected cases, and in two cases (1\%) the type of isolation was airborne transmission (data not shown in table 1).

Table 2 shows the AE frequency, the length of hospital stay in days and the $\mathrm{AE}$ incidence density in both isolated and non-isolated patients. There were 37 AEs detected in 33 of the isolated patients, and 22 AEs in 19 of the nonisolated patients. The incidence of AEs among isolated patients was $18.5 \%$. (95\% CI $13.1 \%$ to $23.9 \%$ ), compared with $11 \%$ (95\% CI $6.7 \%$ to $15.3 \%$ ) in non-isolated patients $(\mathrm{p}<0.09)$.

Among the 33 isolated patients with $\mathrm{AE}$, over half $(63.6 \%)$ were men with a mean age at admission of 67.7 years, the majority $(84.8 \%)$ presenting at least one intrinsic risk factor and more than half $(60.6 \%)$ with at least three intrinsic risk factors at admission. All presented extrinsic risk factors. The median length of hospital stay was 22 days. Moreover, of the 33 isolated patients with AE, 13 experienced an extension of their hospital stay as a result and 4 had a hospital readmission. Moreover, the incidence of patients with AEs among isolated patients was $16.5 \%$ (95\% CI $11.4 \%$ to $21.6 \%$ ) compared with $9.5 \%$ (95\% CI $5.4 \%$ to $13.6 \%$ ) among non-isolated patients $(\mathrm{p}=0.037)$.The incidence density of patients with AEs among isolated patients was 11.8 per 1000 days/patient (95\% CI 7.8 to 15.9 ) compared with 4.3 per 1000 days/ 


\begin{tabular}{|c|c|c|c|c|}
\hline Variable & Isolated patient (N=200) & Non-isolated patient $(\mathrm{N}=200)$ & Total $(\mathrm{N}=400)$ & $P$ value \\
\hline \multicolumn{5}{|l|}{ Sex } \\
\hline Man & $96(48 \%)$ & $95(47.5 \%)$ & $191(47.8 \%)$ & $0.92^{*}$ \\
\hline \multicolumn{5}{|l|}{ Age } \\
\hline \multicolumn{5}{|c|}{ Intrinsic risk factors } \\
\hline Absence & $8(4 \%)$ & $13(6.5 \%)$ & $21(5.2 \%)$ & \multirow[t]{2}{*}{$0.26^{*}$} \\
\hline Presence & $192(96 \%)$ & 187 (93.5\%) & $379(94.8 \%)$ & \\
\hline \multicolumn{5}{|c|}{ No Intrinsic risk factors } \\
\hline 3 or more & $151(75.5 \%)$ & $129(64.5 \%)$ & $280(70 \%)$ & $0.02^{*}$ \\
\hline \multicolumn{5}{|c|}{ Extrinsic risk factors } \\
\hline Absence & $5(2.5 \%)$ & $9(4.5 \%)$ & $14(3.5 \%)$ & \multirow[t]{2}{*}{$0.28^{\star}$} \\
\hline Presence & $195(97.5 \%)$ & $191(95.5 \%)$ & $386(96.5 \%)$ & \\
\hline \multicolumn{5}{|c|}{ Length of hospital stay (days) } \\
\hline Median (IQR) & $9(13)$ & $9(10)$ & $9(11)$ & $0.37 \dagger$ \\
\hline
\end{tabular}

patient (95\% CI 2.4 to 6.3 ) among non-isolated patients $(\mathrm{p}<0.001)$ (data not shown in table 2 ).

Table 3 shows the characteristics of patients with AEs and the impact of these in isolated and non-isolated patients. Among the 19 non-isolated patients with AEs, 63.1\% were women with a mean age of 73.8 years, the majority $(89.4 \%)$ presenting at least one intrinsic risk factor and more than two-thirds $(68.4 \%)$ with at least three intrinsic risk factors at admission. All but one patient presented extrinsic risk factors. The median length of hospital stay was 13 days. Moreover, six patients experienced an extension of their hospital stay as a result, and five had a hospital readmission.

Table 4 shows the results of the logistic regression model which identified the factors associated with the occurrence of an AE. Isolation increased the odds of experiencing an $\mathrm{AE}$ by $74 \%$ (OR 1.74; $95 \%$ CI 0.92 to $3.25)$, although this result was not statistically significant $(p=0.09)$. The presence of extrinsic risk factors did significantly increase the risk of an $\mathrm{AE}$ by a factor of almost 3 , and for each hospital stay day the risk of an $\mathrm{AE}$ rose by $1 \%$. However, the presence of intrinsic risk factors had a statistically significant protective effect against risk of having an AE (OR 0.19; 95\% CI 0.06 to 0.65 ).

Table 5 shows the nature, severity and preventability of AEs. With respect to the nature of the AEs, from among the 37 AEs detected in 33 isolated patients with $\mathrm{AE}$, and the 22 AEs detected in 19 non-isolated patients with AE, the majority corresponded to infections related to hospital care $(48.6 \%$ vs $45.4 \%)$, followed by complications in the care $(29.7 \%$ vs $18.2 \%)$ and the effects of medication $(10.8 \%$ vs $27.3 \%)$ in isolated and non-isolated patients,

Table 2 Adverse events (AEs) frequency, length of hospital stay and AE incidence density in isolated and non-isolated patients

\begin{tabular}{lcccc}
\hline & Isolated patient & Non-isolated patient & Total & P value \\
\hline AEs & 37 & 22 & 59 & 7154 \\
Length of stay in days & 2786 & 4368 & 8.09 & 8.2 \\
AE incidence density/1000 days-patient & 13.3 & 5 & 2.9 to 7.1 & 6.1 to 10.4 \\
$95 \% \mathrm{Cl}$ & 9.0 to 17.6 & & \\
\hline
\end{tabular}

95\% Confidence Interval (Cl)

AEs, adverse events. 
Table 3 Characteristics of patients with adverse events (AEs) and the impact of these in isolated and non-isolated patients

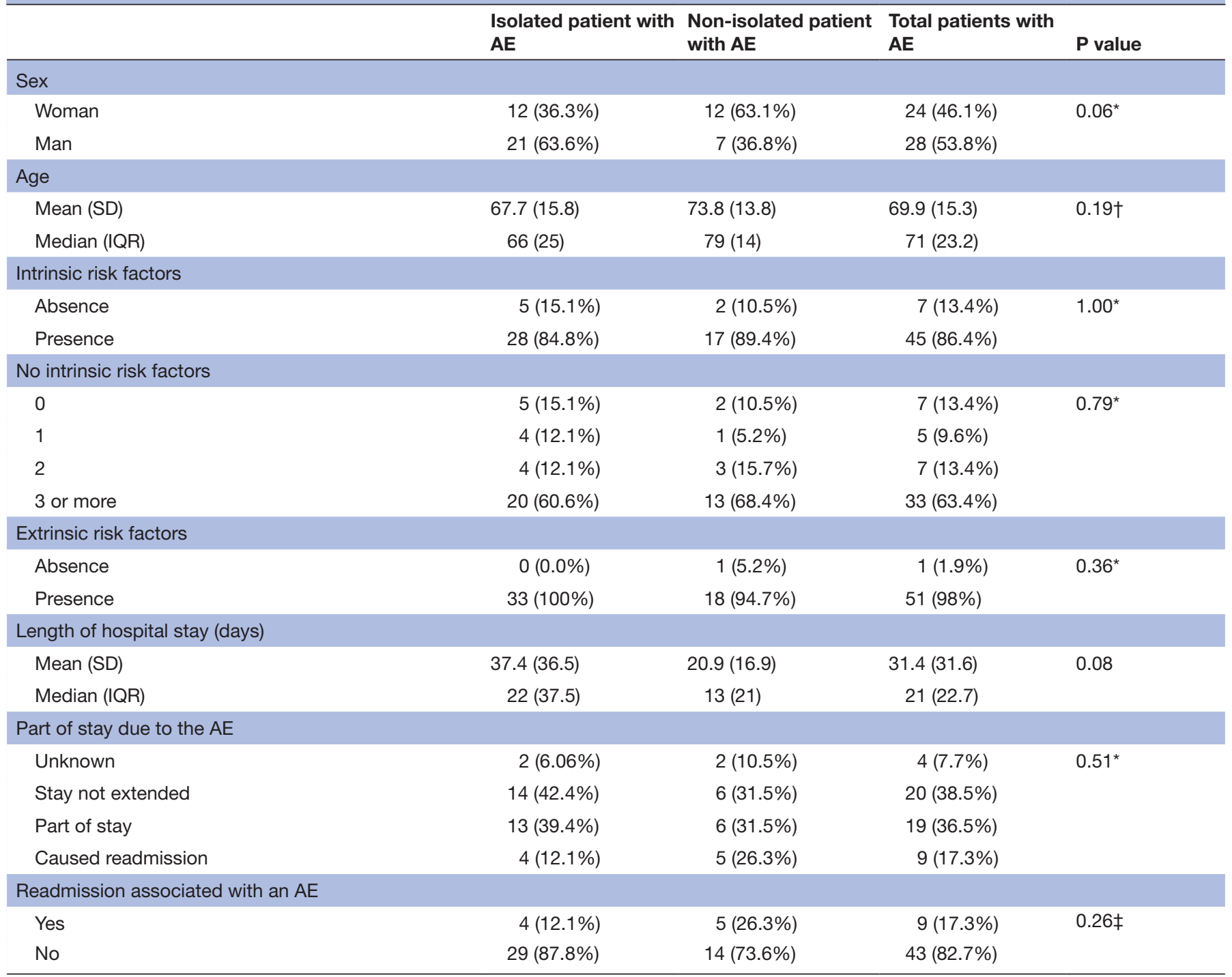

${ }^{*} \chi^{2}$ test

tMann-Whitney U test.

$\ddagger$ Student's t-test.

$\mathrm{AE}$, adverse events; IQR, interquartile range; SD, standard deviation.

Table 4 Results of the logistic regression model which identified the factors associated with the occurrence of an adverse event

\begin{tabular}{llll}
\hline Variables & OR & $\mathbf{9 5 \%} \mathbf{C l}$ & $\mathbf{P}$ value \\
\hline $\begin{array}{l}\text { Isolated patient } \\
\begin{array}{l}\text { Presence of } \\
\text { intrinsic risk } \\
\text { factors }\end{array}\end{array}$ & 1.73 & 0.92 to 3.25 & 0.09 \\
$\begin{array}{l}\text { Presence of } \\
\text { extrinsic risk } \\
\text { factors }\end{array}$ & 2.55 & 0.06 to 0.65 & 0.01 \\
$\begin{array}{l}\text { Stay (days) } \\
\text { Age (years) }\end{array}$ & 1.01 & 1.00 to 1.01 & 0.04 \\
\hline \begin{tabular}{l} 
Sex (man) \\
\hline
\end{tabular} & 1.00 & 0.97 to 1.02 & 0.82 \\
\hline
\end{tabular}

respectively. Of the 37 AEs detected in isolated patients, $48.65 \%$ were considered of minor severity, $43.24 \%$ of moderate severity, and $8.11 \%$ of serious severity. In nonisolated patients, of the $22 \mathrm{AE}$ detected, $50 \%$ were considered minor, $40.91 \%$ moderate and $9.09 \%$ serious. As to the preventability of the AEs, from among the 37 AEs detected in isolated patients, $25(67.5 \%)$ were considered preventable compared with the 22 AEs detected in nonisolated patients, of which $10(52.6 \%)$ were considered preventable.

\section{DISCUSSION}

We observed a higher significant incidence of patients with AEs related to healthcare in isolated patients. These results are supported by the conclusions of the three 
Table 5 Characteristics and impact of adverse events (AEs) in isolated and non-isolated patients

\begin{tabular}{|lll}
\hline AE total (N=59) & $\begin{array}{l}\text { AE in } \\
\text { isolated } \\
\text { patient, } \\
\mathbf{N = 3 7}(\%)\end{array}$ & $\begin{array}{l}\text { AE in non- } \\
\text { isolated } \\
\text { patient, } \\
\mathbf{N}=\mathbf{2 2}(\%)\end{array}$ \\
\hline Nature & & \\
\hline Care-related infections & 48.6 & 45.4 \\
\hline $\begin{array}{l}\text { Complications in care } \\
\text { Effects of medication }\end{array}$ & 29.7 & 18.2 \\
\hline $\begin{array}{l}\text { Complications with a } \\
\text { procedure }\end{array}$ & 10.8 & 27.3 \\
\hline Other & 5.4 & - \\
\hline Severity & 5.4 & 9.1 \\
\hline Minor & & \\
\hline Moderate & 48.6 & 50.0 \\
\hline Serious & 43.2 & 40.9 \\
\hline Preventability & 8.1 & 9.1 \\
\hline Yes & & \\
\hline No & 67.6 & 52.6 \\
\hline
\end{tabular}

AEs, adverse events.

systematic reviews which have examined the relation between $\mathrm{AE}$ in isolated and non-isolated patients. ${ }^{34} 10$

In our study, care-related infections were the most frequent cause of $\mathrm{AE}$ in both groups. On the other hand, in isolated patients, the second most frequent source of AEs related to care complications such as falls, pressure ulcers or electrolyte impairments, followed by medication effects. Whereas in non-isolated patients, the second most frequent causes of AEs were medication effects, followed by care complications.

These results coincide with previous studies that show that isolated patients have an eight times higher probability of experiencing care complications than nonisolated patients. ${ }^{18} 19$ Moreover, studies that focus on contact isolation precautions have identified AEs associated with care complications, including medication errors, nosocomial pneumonia, falls or pressure ulcers. These results may indicate that isolated precautions could have a negative impact on medical professionals' attitude towards the healthcare of these patients, which may be influenced by fears and concerns at exposing themselves to a higher risk of contamination. They could also be due to care complications such as lack of surveillance linked to the extra work required by the isolation precautions.

Other publication highlight that control of infections by multidrug-resistant micro-organisms requires that standard precautions are respected consistently and with all patients. The decision to indicate special isolation precautionary measures requires evaluating the potential excess risk linked to the isolation. ${ }^{20}$
However, other studies did not find differences in the incidence of $\mathrm{AE}$ in patients subjected to isolation precautions compared with non-isolated patients. ${ }^{21}$

In a study in which patients subjected to isolation in intensive care units were compared with a previous nonisolated status no differences were found between the $\mathrm{AE}$ incidence and the isolation status. ${ }^{2}$ This could be due to small sample size, and to the fact that only the hospital time spent in intensive care was analysed, which may have led to an underestimate of the frequency of AEs occurring after patients were transferred to standard hospital care, along with the possible loss of information relating to the retrospective review of cases.

Another study, this time examining the impact of contact precautions on falls, pressure ulcers and transmission of methicillin-resistant Staphylococcus aureus (MRSA) and vancomycin-resistant Enterococcus (VRE) in hospitalised patients, ${ }^{21}$ compared the patients colonised or infected with MRSA or VRE (where contact precautions were discontinued) with other medical-surgical patients. MRSA/VRE patients had higher rates of falls and pressure ulcers, and rates were not affected by removal of contact precautions, suggesting that other factors contribute to these complications.

In our study, the incidence of AEs was associated with longer stays in hospital and a greater number of extrinsic risk factors (such as urinary catheter, peripheral venous catheter, parenteral nutrition, nasogastric tube, immunosuppressive therapy and the number of drugs as regular medication); this coincides with results of a previous study. ${ }^{12}$ However, the presence of intrinsic factors (such as coma, hepatic cirrhosis, coronary heart disease, renal insufficiency, hypertension, diabetes, obesity, hypercholesterolaemia, neoplasia) showed a protective effect against the occurrence of AEs. However, previous studies ${ }^{13} 1422$ indicate greater $\mathrm{AE}$ risk in patients exhibiting higher risk factor levels, both intrinsic and extrinsic. We believe that, for our population, the fact that they had intrinsic factors entailed a higher level of monitoring of these patients. These results were unexpected and further studies will be necessary with higher sample sizes in order to demonstrate whether such a link exists.

\section{Strengths and limitations of this study}

In the present study, several limitations might have arisen. Those inherent to medical records, such as missing data and limited predetermined information included in the AE Monitoring and Control (Sistema de Información para la Vigilancia y Control de Efectos Adversos" (SIVCEA)) System database.

Potential misclassification error might also have occurred based on wrong clinical judgements made by the reviewer of clinical records; however, we tried to minimise this risk by including trained professionals in the screening guidelines (MRF1) and the MRF2 modular form to collect the data of the present study. A previous pilot study was carried out to train reviewers on medical data collection using these guidelines. Selection error 
could also have occurred as a result of the participants not having been randomly selected, that is, exposed patients were included through consecutive sampling; however, we selected non-exposed patients to match with isolated patients as closely as possible, according to the date of admission and reference department, sex, age $( \pm 5$ years) and disease severity measured using the McCabe scale. However, the participants were incorporated over a long period of time (a year and a half) and consecutively, hence if their hospitalisation and isolation had been linked to particular times of the year, this effect would have been minimised by the fact that this incorporation took place at all times of year. Additionally, generalising our results to other populations is beyond the scope of our study.

The present study has several strengths. It is a prospective study with trained reviewers and high-quality measurements performed to collect AE from medical records.

Moreover, this is the first prospective cohort study to examine the relationship between the incidence of AEs in isolated and non-isolated patients in our clinical setting. Furthermore, our study also included patients in isolation because of colonisation with multidrug-resistant microorganisms, and was not limited to patients with infections.

Eventually, the sample size included 400 patients, a larger sample size than previous studies, adequately powered to identify differences between isolated and non-isolated patients.

\section{CONCLUSIONS}

In this study, we observed a higher incidence of AEs in isolated patients compared with non-isolated patients, of which $67.6 \%$ were preventable in isolated patients against $52.6 \%$ in non-isolated patients.

With the increasing problem of antibiotic-resistant bacteria, among others, the need for isolation precautions will continue to increase as a method of reducing nosocomial transmission of multidrug-resistant organisms. However, as we have observed in this study, the decision whether or not to prescribe isolation precautions in a patient implies a potential added risk associated with the isolation process itself. Moreover, the isolated patients, given the greater complexity of their care, require on the one hand a greater awareness of this complex medical situation from care professionals, and on the other hand continuous professional training in the use of both standard isolation precautions and special isolation precautions.

We should also provide information for patients about isolation, as this can represent an opportunity to help with their recovery through minimising the psychological impact of transmission-based precautions.

In light of the results shown in this study, we recommend classifying the precaution recommendations based on the transmission mechanism-drop, contact and airborne transmission-as recommended by the CDC. ${ }^{20}$ Our results can help to prioritise the prescription of transmission-based precautions on specific patients in acute hospital care.

Recent developments-such as the appearance of new rapidly spreading viruses like SARS-CoV-2 alongside the ongoing increase in the incidence of multidrugresistant bacteria requiring particular care in terms of avoiding transmission-render increasingly important the appropriate training of health workers in standard and advanced precautions, so that healthcare is as safe as possible both for patients and health professionals. Also of ever increasing relevance will be the need for appropriate management of the pertinence and duration of precautions relating to transmission in hospitals, while allowing efficient healthcare, in the context of available health resources.

\section{Author affiliations}

${ }^{1}$ Department of Preventive Medicine and Public Health, Hospital Universitari San Juan de Alicante, Sant Joan d'Alacant, Spain

${ }^{2}$ Department of Public Health, History of Science and Gynaecology, Universidad Miguel Hernández, Elche, Spain

${ }^{3}$ Centro de Investigación Biomédica en Red en Epidemiología y Salud Pública (CIBERESP), Madrid, Spain

${ }^{4}$ Preventive Medicine and Public Health, Hospital Clinico Universitario Lozano Blesa, Zaragoza, Spain

${ }^{5}$ Instituto de Investigacion Sanitaria Aragon, Zaragoza, Spain

${ }^{6}$ Department of Preventive Medicine and Public Health, Hospital Politécnico y Universitario La Fe, Valencia, Spain

${ }^{7}$ Preventive Medicine and Public Health, Hospital Universitario Ramon y Cajal, Madrid, Spain

Contributors The study was conceived and designed by: FJP, JMAA and MTGVdC. Data collection: FJP and MdCMG. Data debugging: FJP. Analysis of the data: FJP, JMAA, MTGVdC, MP-V and JJM. Authors of the paper: FJP, JMAA, MTGVdC and MPV. Previous drafts critically reviewed by: FJP, JMAA, MTGVdC, MP-V, MdCMG and CAR. All authors approved the final version of the manuscript.

Funding Ministerio de Economía y Competitividad Instituto de Salud Carlos III PI 13/01921.

Competing interests None declared.

Patient consent for publication Not required.

Ethics approval Institutional review board approval for the study was obtained from Sant Joan d'Alacant University Hospital Ethical Committee (13/315), 3 February 2014.

Provenance and peer review Not commissioned; externally peer reviewed.

Data availability statement All data relevant to the study are included in the article or uploaded as online supplemental information.

Open access This is an open access article distributed in accordance with the Creative Commons Attribution Non Commercial (CC BY-NC 4.0) license, which permits others to distribute, remix, adapt, build upon this work non-commercially, and license their derivative works on different terms, provided the original work is properly cited, appropriate credit is given, any changes made indicated, and the use is non-commercial. See: http://creativecommons.org/licenses/by-nc/4.0/.

ORCID iD

Fátima Jiménez-Pericás http://orcid.org/0000-0001-7393-8567

\section{REFERENCES}

1 Stelfox HT, Bates DW, Redelmeier DA. Safety of patients isolated for infection control. JAMA 2003;290:1899-905.

2 Gutiérrez-Cía I, Aibar-Remón C, Obón-Azuara B, et al. Aislamiento del paciente crítico: ¿riesgo O protección? J Healthc Qual Res 2018;33:250-5. 
3 Abad C, Fearday A, Safdar N. Adverse effects of isolation in hospitalised patients: a systematic review. J Hosp Infect 2010;76:97-102.

4 Morgan DJ, Diekema DJ, Sepkowitz K, et al. Adverse outcomes associated with contact precautions: a review of the literature. Am J Infect Control 2009;37:85-93.

5 Guilley-Lerondeau B, Bourigault C, Guille des Buttes A-C, et al. Adverse effects of isolation: a prospective matched cohort study including 90 direct interviews of hospitalized patients in a French university hospital. Eur J Clin Microbiol Infect Dis 2017;36:75-80.

6 Tran K, Bell C, Stall N, et al. The effect of hospital isolation precautions on patient outcomes and cost of care: a multi-site, retrospective, propensity score-matched cohort study. J Gen Intern Med 2017;32:262-8.

7 Martin EM, Bryant B, Grogan TR, et al. Noninfectious Hospital adverse events decline after elimination of contact precautions for MRSA and VRE. Infect Control Hosp Epidemiol 2018;39:788-96.

8 Gandra S, Barysauskas CM, Mack DA, et al. Impact of elimination of contact precautions on noninfectious adverse events among MRSA and VRE patients. Infect Control Hosp Epidemiol 2018;39:1272-3.

9 World Health Organization. More than words: conceptual framework for the International classification for patient safety version 1.1. Geneva: WHO, 2009. https://www.who.int/patientsafety/taxonomy/ icps_full_report.pdf

10 Purssell E, Gould D, Chudleigh J, et al. Impact of isolation on hospitalised patients who are infectious: systematic review with meta-analysis. BMJ Open 2020;10:e030371.

11 EPINE. EPINE, estudio de prevalencia de infecciones nosocomiales en España. Available: https://epine.es/api/documento-publico/ 2019\%20EPINE\%20Informe\%20Espa\%C3\%B1a\%2027112019.pdf/ reports-esp

12 Aranaz JM, Aibar C, Vitaller J, et al. Estudio Nacional de Efectos Adversos ligados a la Hospitalización. ENEAS 2005. Madrid: Ministerio de Sanidad y Consumo, 2006. https://www. seguridaddelpaciente.es/resources/contenidos/castellano/2006/ ENEAS.pdf
13 Aranaz-Andrés JM, Limón R, Mira JJ, et al. What makes hospitalized patients more vulnerable and increases their risk of experiencing an adverse event? Int J Qual Health Care 2011;23:705-12.

14 Aranaz-Andrés JM, Aibar-Remón C, Vitaller-Burillo J, et al. Impact and preventability of adverse events in Spanish public hospitals: results of the Spanish national study of adverse events (ENEAS). Int $J$ Qual Health Care 2009;21:408-14.

15 María Aranaz J, Limón R, Requena J, et al. Incidencia E impacto de Los efectos adversos en DOS hospitales. Revista de Calidad Asistencial 2005;20:53-60.

16 Woloshynowych M, Neale G, Vincent C. Case record review of adverse events: a new approach. Qual Saf Health Care 2003;12:411-5

17 Siegel JD, Rhinehart E, Healthcare Infection Control Practices Advisory Committee. 2007 guideline for isolation precautions: preventing transmission of infectious agents in healthcare settings. Available: https://www.cdc.gov/infectioncontrol/pdf/guidelines/ isolation-guidelines-H.pdf

18 Zahar JR, Garrouste-Orgeas M, Vesin A, et al. Impact of contact isolation for multidrug-resistant organisms on the occurrence of medical errors and adverse events. Intensive Care Med 2013;39:2153-60.

19 Karki S, Leder K, Cheng AC. Patients under contact precautions have an increased risk of injuries and medication errors: a retrospective cohort study. Infect Control Hosp Epidemiol 2013;34:1118-20.

20 Bueno-Cavanillas A, Cavanillas AB. Precauciones de transmisión POR contacto: Riesgo para El paciente aislado, beneficio para terceros. J Healthc Qual Res 2018;33:247-9.

21 Gandra S, Barysauskas CM, Mack DA, et al. Impact of contact precautions on falls, pressure ulcers and transmission of MRSA and VRE in hospitalized patients. J Hosp Infect 2014;88:170-6.

22 Aranaz-Andrés JM, Aibar-Remón C, Vitaller-Murillo J, et al. Incidence of adverse events related to health care in Spain: results of the Spanish national study of adverse events. J Epidemiol Community Health 2008;62:1022-9. 
Correction: Higher incidence of adverse events in isolated patients compared with non-isolated patients: a cohort study

Jiménez-Pericás F, Gea Velázquez de Castro MT, Pastor-Valero M, et al. Higher incidence of adverse events in isolated patients compared with non-isolated patients: a cohort study. BMJ Open. 2020;10:e035238. doi: 10.1136/bmjopen-2019-035238

This article was previously published with error in affiliation. The below affiliation has been updated and added for both authors, Maria Pastor-Valero and Jesús Maria Aranaz Andrés.

Centro de Investigación Biomédica en Red en Epidemiología y Salud Pública (CIBERESP), Madrid, Spain.

Open access This is an open access article distributed in accordance with the Creative Commons Attribution Non Commercial (CC BY-NC 4.0) license, which permits others to distribute, remix, adapt, build upon this work non-commercially, and license their derivative works on different terms, provided the original work is properly cited, appropriate credit is given, any changes made indicated, and the use is non-commercial. See: http://creativecommons.org/licenses/by-nc/4.0/.

(c) Author(s) (or their employer(s)) 2020. Re-use permitted under CC BY-NC. No commercial re-use. See rights and permissions. Published by BMJ.

BMJ Open 2020;10:e035238corr1. doi:10.1136/bmjopen-2019-035238corr1

A Check for updates 